\title{
Slowing of motor-evacuation function of the stomach after pancreatoduodenal resection: a modern approach to the problem
}

\author{
V. M. Kopchak, O. I. Lytvyn, O. V. Duvalko, L. O. Pererva, S. O. Motelchuk, P. A. Azadov
}

Shalimov National Institute of Surgery and Transplantology, Kyiv

\section{Уповільнення моторно-евакуаційної функції шлунка після панкреатодуоденальної резекції: сучасний погляд на проблему}

В. М. Копчак, О. І. Литвин, О. В. Дувалко, Л. О. Перерва, С. О. Мотельчук, П. А. Азадов

Національний інститут хірургії та трансплантології імені О. О. Шалімова НАМН України, м. Київ

Upon the development of modern diagnostics in recent years, there has been an increase in the incidence of malignant tumors of the hepatobiliary area and the number of radical surgical resections (for example, the incidence of pancreatic cancer in 2018 in Ukraine is almost 2 times higher than in the world) (11.2 and 6.0, respectively, per 100 thousand population). A similar situation with mortality rates -8.7 in Ukraine and 4.5 in the world per 100 thousand population) $[1,2]$.

A method of choice for the treatment of the pancreatobiliary zone tumors, as well as chronic paraduodenal pancreatitis (Groove's pancreatitis), is pancreaticoduodenectomy "PD" [3]. For now, there are many different techniques of pancreaticoduodenectomy, which should prevent postoperative complications and tumoral recurrence.

The well-known world centers report a reduction in mortality after the PD to less than 5\%. Despite such success, the level of postoperative complications remains high - 40 - 60\% [4]. Specific complications after pancreaticoduodenectomy include external pancreatic fistula, delayed gastric emptying (DGE), bile leak, failure of duodenojejunostomy and gastrojejunostomy, intraabdominal fluid collection and hemorrhage. The most common complication of the early postoperative period, which worsens the general condition of the patient and also causes significant discomfort, is delayed gastric emptying with a frequency of $20-55 \%$ according to various authors [5-7].

DGE constitutes an urgent clinical problem, being one of the most common complications, which has a notable impact on patients' recovery, length of hospital stay, quality of life, and delay of further appropriate treatments (e.g., initiation of adjuvant chemotherapy) after PD [8]. This complication is considered a functional disorder or physiolog- ical motor regulation of the stomach, which may be possibly dependent on the technique of gastro- and duodenojejunostomy. The International Study Group on Pancreatic Surgery (ISGPS) has developed an objective and generally accepted definition of the DGE, based on severity and clinical impact $[9,10]$ : vomiting, inability to take oral food, delayed contrast in the stomach more than 4 hours after X-ray examination and reinsertion of the nasogastric tube after its removal. Three stages (A, B and C) were identified, basing on influence on clinical course and postoperative management (see table) [11]. The proposed definition, which includes clinical evaluation of the DHE, will allow an objective and accurate comparison of future clinical trials and will facilitate new interventions and surgical techniques in the field of pancreatic surgery.

The implementation of the consensus definition of ISGPS in clinical practice should standardize the concept of the DGE and provide a common basis on which to analyze the results in different surgical facilities. For the first time the DGE was described as gastroparesis after PD [12]; therefore, these patients should not be classified as having a DGE, whereas some authors may have treated such cases as having tis disorder. This confusion have occurred because the ISGPS criteria did not mention the presence or absence of concomitant complications, exceptions, and methods for the gastroparesis estimation and the cause of the DGE assessment, although the criteria were simple, objective, and measurable. Clarification of the definition is necessary for further analysis of the DGE etiology. The risk factors for DGE are divided into preoperative, intra- and postoperative [13]. Preoperative factors include diabetes mellitus; endobiliary stenting, while the intraoperative - the placement of intra-abdominal drainages; preservation of the pylorus or not, 


\begin{tabular}{l} 
The International Study Group of Pancreatic Surgery definition of delayed gastric emptying after pancreatic \\
surgery \\
\begin{tabular}{|c|c|c|c|c|}
\hline Degree of DGE & Need for a nasogastric tube & $\begin{array}{c}\text { Unable to tolerate solid } \\
\text { oral intake by POD }\end{array}$ & $\begin{array}{c}\text { Vomiting/distension } \\
\text { of the stomach }\end{array}$ & Use of prokinetics \\
\hline A & $4-7$ days or re-staging > POD 3 & 7 & $+/-$ & + - \\
\hline B & $8-14$ days or re-staging > POD 7 & 14 & + & + \\
\hline C & $>14$ days or re-staging > POD 14 & 21 & + & + \\
\hline
\end{tabular} \\
\hline
\end{tabular}

retrocolic and antecolic gastroenterostomy or duodenoenterostomy; condition of the pancreas, vascular reconstruction, and postoperative - pancreatic fistula; sepsis; infection at the site of surgery; re-operation.

The causes of DGE and the mechanisms of its occurrence have not been studied yet. Most studies of DGE, involving surgical techniques such as pyloric preservation or pyloric resection, Billroth I or II reconstruction, with Brown anastomosis, antecolic or retrocolic gastrojejunostomy, and Rouxen-Y reconstruction, analyze each method without comparison only. There are no clear indications and methods for duodeno- and gastrojejunostomy, the issues of technique and tactics of intervention have not been studied and worked out. The technique of reconstruction with an isolated loop of pancreaticogastrostomy and bilio-enteric anastomosis during resection of the pancreatoduodenal area significantly reduces the postoperative frequency of alkaline reflux gastritis [14].

Comparing the standard pylorus-resecting pancreaticoduodenectomy (PrPD) with the pylorus-preserving pancreaticoduodenectomy (PPPD), a higher level of DGE is maintained after pylorus-preserving pancreaticoduodenectomy (PPPD), but not significant. In the randomized controlled trials, resection of the pylorus during PD did not reduce the incidence or severity of DGE $[15,16]$. The development of DGE seems to be multifactorial, not just a pyloric dysfunction. Therefore, preservation of the pylorus should remain the standard of care during PD [17]. However, during PPPD, the original part of the stomach is preserved, what prevents the development of postoperative dumping syndrome, marginal ulceration of gastroenterostomy, and biliary reflux gastritis, which often occur in the patients, who have undergone pylorus-resecting pancreaticoduodenectomy (PrPD) [18]. Analyzing the concentration of motilin in the blood plasma and phase III activity of gastric migrating motor complex have shown, that the duodenal passage preservation is important to maintain gastric motility and prevent the gastric motor evacuation function disorder [20, 21]. As opposed to these findings, there are facts to suggest, that PD with resection of the pylorus (PrPD) is comparatively better or even superior to that with the preservation of the pylorus pancreaticoduodenectomy (PPPD) in terms of the food consumption and DGE [22-25]. Therefore, the clinical significance of the pylorus preservation requires further research. There was a tendency to increase of the DGE morbidity rate in the patients with retrocolic versus ante- colic reconstruction, but this was not statistically significant. According to V.M. Kopchak (2010) [26] and N. Peparini (2012) [27], the inflammatory process in the area, anatomically close to duodeno- or gastro-jejunostomy, constitutes a primary cause of postoperative DGE, and reconstruction in the anterior position of the colon allows to dislocate the pancreatic stump and pancreatoenteroanastomosis from stomach and the small bowel stump.

In our practice, we usually use the Child method for reconstruction. After the of the pancreatic head removal, the small intestine stump rises through the mesocolon, on which the anastomoses are formed alternately: pancreatico-, hepaticoentero- and prefrontal gastro- or duodenoenteroanastomosis. The procedures efficacy and effects on delayed gastric emptying were not determined.

Due to the achievement of laparoscopic surgical methods, the anastomosis formation, using a linear suturing device, is now widely used in the alimentary tract post-PD recomstruction. The Roux-en-Y anastomosis with a laparoscopic linear suturing device, where gastrojejunostomy is performed using a functional perforated anastomosis in combination with a Brown anastomosis, is a general method of reconstruction after laparoscopic distal gastrectomy [28, 29]. The advantages of the bonded side-to-side anastomosis include a standardized approach independent of the surgeon, relative ease as a reconstruction technique, potential reduction of anastomosis leakage [30], and avoidance of anastomotic edema and subsequent stricture formation [31]. However, the clinical efficacy of bonded lateral gastroenteroanastomosis to reduce the risk of the DGE and its advantage over conventional manual sutured end to side anastomosis after pancreaticoduodenectomy remains uncertain [32].

The literature describes rare cases of the stapled linear devices application for the gastroenteroanastomosis and duodenoenteroanastomosis formation in these settings. At present, the techniques for forming of anastomoses, using circular suturing tools, such as those, applied in esophageal surgery, for example, have not been developed or analyzed.

The introduction of mechanical techniques of gastroand duodenojejunostomy with the help of staplers remains a topic for discussion. Despite the widespread use of mechanical sutures/fasteners in gastrointestinal surgery, the application of these devices for reconstruction remains rare. Certain groups of surgeons report the cases of duodenoand gastro- jejunostomy reconstruction with staplers. While linear or circular staplers involved, the anteoclic or retroco- 
lic reconstruction on a Roux-en-Y loop is performed [33]. The authors have demonstrated, that the rate of slowing of gastric emptying was lower in patients, who underwent a hardware gastro/duodenojejunostomy, than in those, who underwent reconstruction, sewn by hand. The researchers have founded, that the recovery time of oral food intake was significantly shorter in the group of anastomoses, sutured by the device, than in the group, sewn by hand. Even the exact mechanism of improvement in the ingestion and DGE by mechanical anastomosis remains unknown. One possible explanation is that edema around the anastomosis area can be prevented by suturing with a hardware stapler, especially in the early postoperative period. Never the less, the study has disadvantages of small sample of patients, comparison with classical techniques and their analysis.

The surgical procedure involves reconstruction of the pancreatic, biliary and digestive systems, what requires a significant amount of time. Taking into account, that a prolonged surgery constitutes a risk factor for mortality and postoperative complications [34-36], it is necessary to make an effort to reduce the surgery time by improving surgical skills and techniques.

The exact pathogenesis of the impaired motor-evacuation function of the stomach is still unclear. Technical approaches to pancreatic resection and postoperative complications continue to play a causative role in the DGE etiology. Operative studies suggest, that classical Whipple surgery, PPPD, antecolic versus retrocolic gastric/duodenal reconstruction, pancreaticogastrostomy versus pancreaticojejunostomy, gastroduodenal and right gastric artery preservation may affect this function [37].

The effects of pancreaticojejunostomy on the DGE occurrence and formation of external pancreatic fistula also remain unexplored issues. Intra-abdominal complications, including pancreatic fistula, have been closely associated with gastrostasis. Concerning the pancreatic reconstruction, a DGE is developed more often during the pancreatogastroanastomosis repair, than in the pancreatojejunostomy [38]. In addition, a DGE with intra-abdominal complications is more common in patients, undergoing pancreatogastroanastomosis, even though intra-abdominal complications have occurred with equal frequency in both groups. The need for a clear understanding of techniques and methods for the duodenoenteroanastomosis and gastroenteroanastomosis formation, depending on the state of the pancreas, also remains an important factor in the prevention of both - a DGE and external pancreatic fistula.

No less important is the need for a probe installment for enteral nutrition and a naso-gastric tube during pancreaticoduodenectomy. Most post-PD patients have significant nausea and vomiting, which prevents early enteral nutrition. Contrary to previous beliefs, nausea and vomiting were not the results of a previously removed nasogastric tube. Delay of the nasogastric tube for a longer time, have led to the delayed onset of nausea or vomiting and prolonged the patient's discomfort only [39]. There are findings, that a routine use of nasogastric tube is unnecessary in elective abdominal surgery, because it do not impact a postoperative morbidity significantly $[40,41]$. When performing a pancreaticogastrostomy (PG), there is a tendency to delay the nasogastric tube longer, trying to decompress the stomach and reduce the risk of anastomotic leakage. The authors report a significant improvement in intestinal motility and gastric emptying, thereby reducing a DGE occurrence. The importance of postoperative management of the patient have led to development and implementation of the enhanced recovery programs after surgery [42], which includes a multidisciplinary team approach and a thoughtful review of all aspects of surgical and postoperative care, such as optimal pain control (including regional anesthesia), minimally invasive techniques, and aggressive postoperative rehabilitation (nutrition support, physical activity, etc.). From the patient's point of view, a decrease in postoperative length of stay is related to a decrease of DGE and early return to normal nutrition and digestive function, as well as reduction in pain and a faster back to preoperative mobility levels, leading to overall postoperative improvement [43]. Some studies have focused on considering the effect of early enteral nutrition on the occurrence of the DGE only, without considering the methods of formation of anastomoses.

DGE after pancreaticoduodenectomy is not life-threatening and can be treated conservatively, though it leads to discomfort and significant extension of hospital stay and increases the treatment cost.

Summarizing the above mentioned data in modern literature and personal experience, we can say about the lack of methods, techniques, and indications for the formation of duodeno- jejunostomy, and gastro- jejunostomy, which would significantly reduce or prevent the occurrence of a DGE in early postoperative period.

At the same time, the authors report, that during the anastomoses formation they rely on their own experience of their performance in pancreaticoduodenectomy. It is necessary to propose the most optimal way of a duodeno- jejunostomy and gastro- jejunostomy formation to prevent the DGE occurrence in early postoperative period after PD.

Funding. This scientific work is performed within the comprehensive research.

Conflicts of interest. There is no potential or apparent conflict of interest associated with this manuscript.

\section{References}

1. Kopchak VM, Zaivelieva II. Pancreatic cancer: Ukrainian and world tendencies. Practical oncology. 2020;3(1):42-5. Ukrainian. doi: 10.22141/2663-3272.3.1.2020.209824.

2. Duffy JP, Hines OJ, Liu JH, Ko CY, Cortina G, Isacoff WH, et al. Improved survival for adenocarcinoma of the ampulla of Vater: fiftyfive consecutive resections. Arch Surg. 2003 Sep;138(9):941-8; discussion 948-50. doi: 10.1001/archsurg.138.9.941. PMID: 12963649.

3. Yamaue H. History of pancreatic surgery in Japan: Respect to the Japanese pioneers of pancreatic surgery. Ann Gastroenterol Surg. 2020 
Mar 4;4(2):118-25. doi: 10.1002/ags3.12320. PMID: 32258976; PMCID: PMC7105840.

4. Kopchak VM, Pererva LA, Khomiak IV, Duvalko AV, Khanenko VV, Andronik SV, et al. Preventing of the postoperative complications in patients after pancreaticoduodenectomy. Problems of clinical pediatrics. 2020;(3):32-40. Ukrainian. doi: 10.24144/19986475.2020.49.32-40.

5. Cai X, Zhang M, Liang C, Xu Y, Yu W. Delayed gastric emptying after Pancreaticoduodenectomy: a propensity score-matched analysis and clinical Nomogram study. BMC Surg. 2020 Jul 9;20(1):149. doi: 10.1186/s12893-020-00809-5. PMID: 32646466; PMCID: PMC7346444.

6. Snyder RA, Ewing JA, Parikh AA. Delayed gastric emptying after pancreaticoduodenectomy: A study of the national surgical quality improvement program. Pancreatology. 2020 Mar;20(2):205-10. doi: 10.1016/j.pan.2019.12.003. Epub 2019 Dec 16. PMID: 31875832.

7. Cakir M, Akinci M, Akturk OM. Delayed Gastric Emptying as a Complication of Whipple's Procedure: Could it be Much Less Frequent than Anticipated? Could the Definition Be Revised? A Single Center Experience. Medeni Med J. 2020;35(3):181-7. doi: 10.5222/ MMJ.2020.02222. Epub 2020 Sep 30. PMID: 33110669; PMCID: PMC7584264.

8. Hackert T, Bruckner T, Dörr-Harim C, Diener MK, Knebel P, Hartwig W, et al. Pylorus resection or pylorus preservation in partial pancreatico-duodenectomy (PROPP study): study protocol for a randomized controlled trial. Trials. 2013 Feb 14;14:44. doi: 10.1186/1745-6215-14-44. PMID: 23410208; PMCID: PMC3599830.

9. Dusch N, Lietzmann A, Barthels F, Niedergethmann M, Rückert F, Wilhelm TJ. International Study Group of Pancreatic Surgery Definitions for Postpancreatectomy Complications: Applicability at a High-Volume Center. Scand J Surg. 2017 Sep;106(3):216-23. doi: 10.1177/1457496916680944. Epub 2017 Apr 4. PMID: 28376656.

10. Wente MN, Bassi C, Dervenis C, Fingerhut A, Gouma DJ, Izbicki JR, et al. Delayed gastric emptying (DGE) after pancreatic surgery: a suggested definition by the International Study Group of Pancreatic Surgery (ISGPS). Surgery. 2007 Nov;142(5):761-8. doi: 10.1016/j.surg.2007.05.005. PMID: 17981197.

11. Malleo G, Crippa S, Butturini G, Salvia R, Partelli S, Rossini $\mathrm{R}$, et al. Delayed gastric emptying after pylorus-preserving pancreaticoduodenectomy: validation of International Study Group of Pancreatic Surgery classification and analysis of risk factors. HPB (Oxford). 2010 Nov;12(9):610-8. doi: 10.1111/j.14772574.2010.00203.x. Epub 2010 Sep 2. PMID: 20961369; PMCID: PMC2999788.

12. Patti MG, Pellegrini CA, Way LW. Gastric emptying and small bowel transit of solid food after pylorus-preserving pancreaticoduodenectomy. Arch Surg. 1987 May;122(5):528-32. doi: 10.1001/ archsurg.1987.01400170034004. PMID: 3579562.

13. Parmar AD, Sheffield KM, Vargas GM, Pitt HA, Kilbane EM, Hall $\mathrm{BL}$, et al. Factors associated with delayed gastric emptying after pancreaticoduodenectomy. HPB (Oxford). 2013 Oct;15(10):76372. doi: 10.1111/hpb.12129. Epub 2013 Jul 22. PMID: 23869542; PMCID: PMC3791115.

14. Krishna A, Bansal VK, Kumar S, Sridhar P, Kapoor S, Misra MC, et al. Preventing Delayed Gastric Emptying After Whipple's Pro-
cedure-Isolated Roux Loop Reconstruction With Pancreaticogastrostomy. Indian J Surg. 2015 Dec;77(Suppl 2):703-7. doi: 10.1007/ s12262-013-0992-3. Epub 2013 Nov 12. PMID: 26730093; PMCID: PMC4692950.

15. Hackert T, Probst P, Knebel P, Doerr-Harim C, Bruckner T, Klaiber U, et al. Pylorus Resection Does Not Reduce Delayed Gastric Emptying After Partial Pancreatoduodenectomy: A Blinded Randomized Controlled Trial (PROPP Study, DRKS00004191). Ann Surg. 2018 Jun;267(6):1021-7. doi: 10.1097/SLA.0000000000002480. PMID: 28885510.

16. Singh AN, Kilambi R. Pylorus Resection Does Not Reduce Delayed Gastric Emptying After Partial Pancreatoduodenectomy: A Blinded Randomized Controlled Trial. Ann Surg. 2018 Dec;268(6):e72-e3. doi: 10.1097/SLA.0000000000002641. PMID: 29261525.

17. Kawai M, Tani M, Hirono S, Miyazawa M, Shimizu A, Uchiyama $\mathrm{K}$, et al. Pylorus ring resection reduces delayed gastric emptying in patients undergoing pancreatoduodenectomy: a prospective, randomized, controlled trial of pylorus-resecting versus pylorus-preserving pancreatoduodenectomy. Ann Surg. 2011 Mar;253(3):495-501. doi: 10.1097/SLA.0b013e31820d98f1. PMID: 21248633.

18. Yamaguchi K. Pancreatoduodenectomy for bile duct and ampullary cancer. J Hepatobiliary Pancreat Sci. 2012 May;19(3):210 5. doi: 10.1007/s00534-011-0480-8. PMID: 22170385; PMCID: PMC3311854.

19. Hackert T, Hinz U, Hartwig W, Strobel O, Fritz S, Schneider L, et al. Pylorus resection in partial pancreaticoduodenectomy: impact on delayed gastric emptying. Am J Surg. 2013 Sep;206(3):296-9. doi: 10.1016/j.amjsurg.2012.10.042. Epub 2013 Jun 24. PMID: 23806827.

20. Kim YJ, Shin SH, Han IW, Ryu Y, Kim N, Choi DW, et al. Clinical outcomes of pancreaticoduodenectomy for pancreatic ductal adenocarcinoma depending on preservation or resection of pylorus. Ann Hepatobiliary Pancreat Surg. 2020 Aug 31;24(3):26976. doi: 10.14701/ahbps.2020.24.3.269. PMID: 32843591; PMCID: PMC7452792.

21. Zhou Y, Lin L, Wu L, Xu D, Li B. A case-matched comparison and meta-analysis comparing pylorus-resecting pancreaticoduodenectomy with pylorus-preserving pancreaticoduodenectomy for the incidence of postoperative delayed gastric emptying. HPB (Oxford). 2015 Apr;17(4):337-43. doi: 10.1111/hpb.12358. Epub 2014 Nov 11. PMID: 25388024; PMCID: PMC4368398.

22. Hayashibe A, Kameyama M, Shinbo M, Makimoto S. The surgical procedure and clinical results of subtotal stomach preserving pancreaticoduodenectomy (SSPPD) in comparison with pylorus preserving pancreaticoduodenectomy (PPPD). J Surg Oncol. 2007 Feb 1;95(2):106-9. doi: 10.1002/jso.20608. PMID: 17262740.

23. Akizuki E, Kimura Y, Nobuoka T, Imamura M, Nishidate T, Mizuguchi T, et al. Prospective nonrandomized comparison between pylorus-preserving and subtotal stomach-preserving pancreaticoduodenectomy from the perspectives of DGE occurrence and postoperative digestive functions. J Gastrointest Surg. 2008 Jul;12(7):118592. doi: 10.1007/s11605-008-0513-z. Epub 2008 Apr 22. PMID: 18427904.

24. Kurahara H, Takao S, Shinchi H, Mataki Y, Maemura K, Sakoda M, et al. Subtotal stomach-preserving pancreaticoduodenectomy (SSPP) prevents postoperative delayed gastric emptying. J 
Surg Oncol. 2010 Nov 1;102(6):615-9. doi: 10.1002/jso.21687. PMID: 20721956.

25. Hackert T, Probst P, Büchler MW. Response: Pylorus Resection Does Not Reduce Delayed Gastric Emptying After Partial Pancreatoduodenectomy: A Blinded Randomized Controlled Trial. Ann Surg. 2018 Dec;268(6):e73-e74. doi: 10.1097/SLA.0000000000002647. PMID: 29266007.

26. Kopchak VM, Kopchak KV, Khomiak IV, Duvalko AV, Borisov $\mathrm{BV}$, Davidenko NG. Intraoperative possibilities of reduction of postoperative complications frequency in pancreaticoduodenal resection on its reconstructive stage. Klin Khir. 2010 Apr;(4):21-3. Russian. PMID: 20568503.

27. Peparini N, Chirletti P. Does antecolic reconstruction decrease delayed gastric emptying after pancreatoduodenectomy? World J Gastroenterol. 2012 Dec 7;18(45):6527-31. doi: 10.3748/wjg.v18. i45.6527. PMID: 23236224; PMCID: PMC3516209.

28. Noshiro H, Ohuchida K, Kawamoto M, Ishikawa M, Uchiyama A, Shimizu S, et al. Intraabdominal Roux-en-Y reconstruction with a novel stapling technique after laparoscopic distal gastrectomy. Gastric Cancer. 2009;12(3):164-9. doi: 10.1007/s10120-009-0520-0. Epub 2009 Nov 5. PMID: 19890697.

29. Kojima K, Yamada H, Inokuchi M, Kawano T, Sugihara K. A comparison of Roux-en-Y and Billroth-I reconstruction after laparoscopy-assisted distal gastrectomy. Ann Surg. 2008 Jun;247(6):962-7. doi: 10.1097/SLA.0b013e31816d9526. PMID: 18520223.

30. Resegotti A, Astegiano M, Farina EC, Ciccone G, Avagnina G, Giustetto A, et al. Side-to-side stapled anastomosis strongly reduces anastomotic leak rates in Crohn's disease surgery. Dis Colon Rectum. 2005 Mar;48(3):464-8. doi: 10.1007/s10350-004-0786-6. PMID: 15719193.

31. Murata Y, Tanemura A, Kato H, Kuriyama N, Azumi Y, Kishiwada M, et al. Superiority of stapled side-to-side gastrojejunostomy over conventional hand-sewn end-to-side gastrojejunostomy for reducing the risk of primary delayed gastric emptying after subtotal stomach-preserving pancreaticoduodenectomy. Surg Today. 2017 Aug;47(8):1007-17. doi: 10.1007/s00595-017-1504-z. Epub 2017 Mar 23. PMID: 28337543; PMCID: PMC5493708.

32. Sato N, Yabuki K, Kohi S, Mori Y, Minagawa N, Tamura T, et al. Stapled gastro/duodenojejunostomy shortens reconstruction time during pylorus-preserving pancreaticoduodenectomy. World J Gastroenterol. 2013 Dec 28;19(48):9399-404. doi: 10.3748/wjg.v19. i48.9399. PMID: 24409068; PMCID: PMC3882414.

33. Ball CG, Pitt HA, Kilbane ME, Dixon E, Sutherland FR, Lillemoe KD. Peri-operative blood transfusion and operative time are quality indicators for pancreatoduodenectomy. HPB (Oxford). 2010 Sep;12(7):465-71. doi: 10.1111/j.1477-2574.2010.00209.x. PMID: 20815855; PMCID: PMC3030755.
34. Billingsley KG, Hur K, Henderson WG, Daley J, Khuri SF, Bell RH Jr. Outcome after pancreaticoduodenectomy for periampullary cancer: an analysis from the Veterans Affairs National Surgical Quality Improvement Program. J Gastrointest Surg. 2003 May-Jun;7(4):484-91. doi: 10.1016/S1091-255X(03)00067-2. PMID: 12763405.

35. Pecorelli N, Balzano G, Capretti G, Zerbi A, Di Carlo V, Braga M. Effect of surgeon volume on outcome following pancreaticoduodenectomy in a high-volume hospital. J Gastrointest Surg. 2012 Mar;16(3):518-23. doi: 10.1007/s11605-011-1777-2. Epub 2011 Nov 15. PMID: 22083531.

36. Kopchak VM, Khomiak IV, Kopchak KV, Duvalko OV. New techniques of surgical treatment of malignant tumors of the pancreas head and periampullary. Surgery of Ukraine. 2012;(4):31-6. Ukrainian.

37. Hayama S, Senmaru N, Hirano S. Delayed gastric emptying after pancreatoduodenectomy: comparison between invaginated pancreatogastrostomy and pancreatojejunostomy. BMC Surg. $2020 \mathrm{Apr}$ 3;20(1):60. doi: 10.1186/s12893-020-00707-w. PMID: 32245470; PMCID: PMC7118865.

38. Balzano G, Zerbi A, Braga M, Rocchetti S, Beneduce AA, Di Carlo V. Fast-track recovery programme after pancreatico- duodenectomy reduces delayed gastric emptying. Br J Surg. 2008 Nov;95(11):1387-93. doi: 10.1002/bjs.6324. PMID: 18844251.

39. Bergeat D, Merdrignac A, Robin F, Gaignard E, Rayar M, Meunier B, et al. Nasogastric Decompression vs No Decompression After Pancreaticoduodenectomy: The Randomized Clinical IPOD Trial. JAMA Surg. 2020 Sep 1;155(9):e202291. doi: 10.1001/jamasurg.2020.2291. Epub 2020 Sep 16. PMID: 32667635; PMCID: PMC7364368.

40. Baroutjian A, Sanchez C, Elkbuli A. Systematic Nasogastric Tube Decompression Following Pancreaticoduodenectomy-Is it Safe? JAMA Surg. 2021 Mar 1;156(3):293. doi: 10.1001/jamasurg.2020.5677. PMID: 33377897.

41. Shao Z, Jin G, Ji W, Shen L, Hu X. The role of fast-track surgery in pancreaticoduodenectomy: a retrospective cohort study of 635 consecutive resections. Int J Surg. 2015 Mar;15:129-33. doi: 10.1016/j.ijsu.2015.01.007. Epub 2015 Jan 20. PMID: 25615646.

42. Schwab M, Brindl N, Studier-Fischer A, Tu T, Gsenger J, Pilgrim $\mathrm{M}$, et al. Postoperative complications and mobilisation following major abdominal surgery with vs. without fitness tracker-based feedback (EXPELLIARMUS): study protocol for a student-led multicentre randomised controlled trial (CHIR-Net SIGMA study group). Trials. 2020 Mar 23;21(1):293. doi: 10.1186/s13063-0204220-8. PMID: 32293519; PMCID: PMC7092422.

Received: 16.11 .2020 